Check for updates

Cite this: RSC Adv., 2021, 11, 33245

Received 3rd September 2021 Accepted 5th October 2021

DOI: 10.1039/d1ra06632c

rsc.li/rsc-advances

\section{The radical scavenging activity of muriolide in physiological environments: mechanistic and kinetic insights into double processes $\uparrow$}

\begin{abstract}
Nguyen Thi Hoa, ${ }^{a}$ Le Thi Ngoc Van ${ }^{\mathrm{b}}$ and Quan V. Vo (iD *a
Muriolide (MO) is a natural lactone that was isolated from Ranunculus muricatus. This compound exhibited good antioxidant activity in some experiments; however, the radical scavenging activity of $\mathrm{MO}$ in physiological environments has not been studied yet. In this study, the reaction between hydroperoxyl radical and $\mathrm{MO}$ was investigated in physiological environments by using density functional theory (DFT) calculations. It was found that $\mathrm{MO}$ exhibits excellent antiradical activity in water at physiological $\mathrm{pH}$ ( $k=$ $1.05 \times 10^{8} \mathrm{M}^{-1} \mathrm{~s}^{-1}$ ) by the single electron transfer mechanism of the anion state. However, the activity in lipid media is moderate with $k=2.54 \times 10^{4} \mathrm{M}^{-1} \mathrm{~s}^{-1}$ and is defined by the formal hydrogen transfer pathway. The antiradical reactions can occur in double processes; however, the first reaction may define the $\mathrm{HOO}^{\circ}$ radical scavenging activity of $\mathrm{MO}$. Compared with typical natural antioxidants, the antiradical activity of $\mathrm{MO}$ against $\mathrm{HOO}^{\circ}$ radicals is slightly lower than Trolox in pentyl ethanoate. However, the activity of $\mathrm{MO}$ is approximately 808 times faster than that of the reference in aqueous solution. Thus, the data suggest that $\mathrm{MO}$ is a promising natural radical scavenger in the physiological environment.
\end{abstract}

\section{Introduction}

Ranunculus muricatus, which belongs to the genus Ranunculus (Ranunculaceae), is known as spiny fruit buttercup in Asia, Australia, South America, and Europe. ${ }^{1}$ The plant has been used as a traditional drug to treat urinary infections, jaundice, diarrhea, dysentery, eczema, leprosy, and ringworm infection..$^{2-4} R$. muricatus is also used as a remedy for coughs and asthma and a deworming agent for all types of livestock. ${ }^{5,6}$ Studies showed that $R$. muricatus exhibited cytotoxic, antibacterial, antifungal, and particularly antioxidant properties. ${ }^{7,8}$ The antioxidant activity of $R$. muricatus may be related to phenolic compounds such as flavonoids, flavonoid glycosides, and lactones found in the plant. ${ }^{7,9,10}$

Muriolide (MO, Fig. 1) is a natural lactone that has been isolated from Ranunculus muricatus. ${ }^{9}$ This compound exhibited good antioxidant activity against the DPPH radical scavenging activity $\left(\mathrm{IC}_{50}=56.9 \mu \mathrm{M}\right)$ and lipoxygenase enzyme testing $\left(\mathrm{IC}_{50}\right.$ $=68.3 \mu \mathrm{M})$. Thus the radical scavenging activity of MO, particularly in the physiological systems, needs to be investigated; however, this issue has not been mentioned yet. Previous studies have shown that the computational method is one of the most convenient means of examining the relationship between

${ }^{a}$ The University of Danang - University of Technology and Education, Danang 550000, Vietnam.E-mail:vvquan@ute.udn.vn ${ }^{b}$ Duy Tan University, Danang 550000, Vietnam

$\dagger$ Electronic supplementary information (ESI) available. See DOI: 10.1039/d1ra06632c structures and biological activity in the development of new medicines, such as antioxidants with increased activities. ${ }^{\mathbf{1 1 - 1 5}}$ Therefore, in this study, the antiradical activity of MO was thoroughly evaluated in double processes by using quantum calculations. In addition, the effects of solvents and molecule structure on the activity were also considered.

\section{Computational details}

Calculations were carried out with the Gaussian 09 suite of programs ${ }^{16}$ by using the M06-2X/6-311++G(d,p) method. ${ }^{17}$ The M06-2X functional is one of the most reliable methods to study thermodynamics and the kinetics of radical reactions, ${ }^{\mathbf{1 8 - 2 0}}$ and widely used to evaluate the antiradical scavenging activity in solvents (water for polar media and pentyl ethanoate for lipid environments) ${ }^{\mathbf{1 5 , 2 1}}$ with low errors compared to experimental<smiles>COC(=O)C(Cc1ccc(O)c(O)c1)OC1(C)C(=O)OCC1O</smiles>

Muriolide (MO)

Fig. 1 Molecular structure of muriolide (MO). 
data $\left(k_{\text {calc }} / k_{\exp }\right.$ ratio $\left.=1-2.9\right){ }^{21-25}$ The kinetic calculations were performed following the quantum mechanics-based test for the overall free radical scavenging activity (QM-ORSA) protocol, ${ }^{12,21}$ with the SMD method for solvent effects, ${ }^{26}$ by the Eyringpy code. ${ }^{24,27}$ All of the species have been optimized directly in the specific environments, i.e. gas phase, pentyl ethanoate and water. The rate constant was calculated by using the conventional transition state theory (TST) and $1 \mathrm{M}$ standard state at 298.15 K..$^{24,25,27-32}$

$$
k=\sigma \kappa \frac{k_{\mathrm{B}} T}{h} \mathrm{e}^{-\left(\Delta G^{\mp}\right) / R T}
$$

where $\sigma$ is the reaction symmetry number, ${ }^{33,34} \kappa$ contains the tunneling corrections calculated using the Eckart barrier, ${ }^{35} k_{\mathrm{B}}$ is the Boltzmann constant, $h$ is the Planck constant, $\Delta G^{\neq}$is the Gibbs free energy of activation. The Marcus Theory was used to estimate the reaction barriers of single electron transfer (SET) reactions. ${ }^{36-38}$ The free energy of reaction $\Delta G^{\neq}$for the SET pathway was computed following the eqn (2) and (3).

$$
\begin{gathered}
\Delta G_{\mathrm{SET}}^{\neq}=\frac{\lambda}{4}\left(1+\frac{\Delta G_{\mathrm{SET}}^{0}}{\lambda}\right)^{2} \\
\lambda \approx \Delta E_{\mathrm{SET}}-\Delta G_{\mathrm{SET}}^{0}
\end{gathered}
$$

where $\Delta G_{\mathrm{SET}}$ is the Gibbs energy of reaction, $\Delta E_{\mathrm{SET}}$ is the nonadiabatic energy difference between reactants and vertical products for SET. ${ }^{39,40}$

For rate constants that were close to the diffusion limit a correction was applied to yield realistic results. ${ }^{21}$ The apparent rate constants $\left(k_{\mathrm{app}}\right)$ were calculated following the CollinsKimball theory in the solvents at $298.15 \mathrm{~K}^{\mathbf{4 1}}$ the steady-state Smoluchowski rate constant $\left(k_{\mathrm{D}}\right)$ for an irreversible bimolecular diffusion-controlled reaction was calculated following the literature as corroding to eqn (4) and (5). ${ }^{\mathbf{2 1 , 4 2}}$

$$
\begin{array}{r}
k_{\mathrm{app}}=\frac{k_{\mathrm{TST}} k_{\mathrm{D}}}{k_{\mathrm{TST}}+k_{\mathrm{D}}} \\
k_{\mathrm{D}}=4 \pi R_{\mathrm{AB}} D_{\mathrm{AB}} N_{\mathrm{A}}
\end{array}
$$

where $R_{\mathrm{AB}}$ is the reaction distance, $N_{\mathrm{A}}$ is the Avogadro constant, and $D_{\mathrm{AB}}=D_{\mathrm{A}}+D_{\mathrm{B}}\left(D_{\mathrm{AB}}\right.$ is the mutual diffusion coefficient of the reactants $\mathrm{A}$ and $\mathrm{B}),{ }^{4 \mathbf{1}, \mathbf{4 3}}$ where $D_{\mathrm{A}}$ or $D_{\mathrm{B}}$ is estimated using the Stokes-Einstein formulation (6). ${ }^{\mathbf{4 4 , 4 5}}$

$$
D_{\mathrm{A} \text { or B }}=\frac{k_{\mathrm{B}} T}{6 \pi \eta a_{\mathrm{A} \text { or B }}}
$$

$\eta$ is the viscosity of the solvents (i.e. $\eta\left(\mathrm{H}_{2} \mathrm{O}\right)=8.91 \times 10^{-4} \mathrm{~Pa} \mathrm{~s}$, $\eta$ (pentyl ethanoate $)=8.62 \times 10^{-4} \mathrm{~Pa} \mathrm{~s}$ ) and $a$ is the radius of the solute that was obtained in Gaussian calculations.

The solvent cage effects were included following the corrections proposed by Okuno, ${ }^{\mathbf{4 6}}$ adjusted with the free volume theory according to the Benson correction ${ }^{21,47-49}$ to reduce overpenalizing entropy losses in solution. All transition states were characterized by the existence of only one single imaginary frequency. Intrinsic coordinate calculations (IRCs) were performed to ensure that each transition state (TS) is connected correctly with the pre-complex (RC) and post-complex (PC).

\section{Results and discussion}

\subsection{The gas phase evaluation}

Study of the structure of the MO showed that the molecule can adopt multiple conformational structures. Thus, as an initial step, the possibility of MO conformers was examined ${ }^{50}$ and then the M06-2X/6-311++G(d,p) method was used to analyze the six

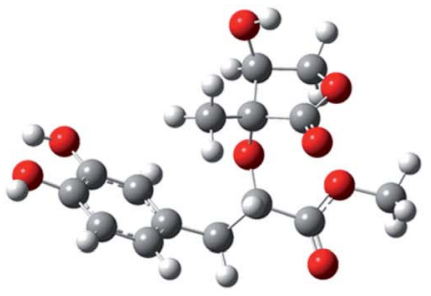

MO $\left(\Delta \mathrm{G}^{\circ}=0,99.59 \%\right)$

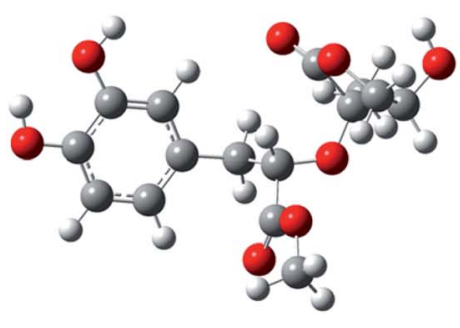

$\operatorname{MO3}\left(\Delta \mathrm{G}^{\circ}=4.7,0.04 \%\right)$

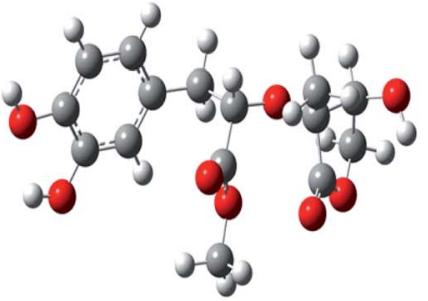

$\operatorname{M01}\left(\Delta G^{\circ}=3.6,0.23 \%\right)$

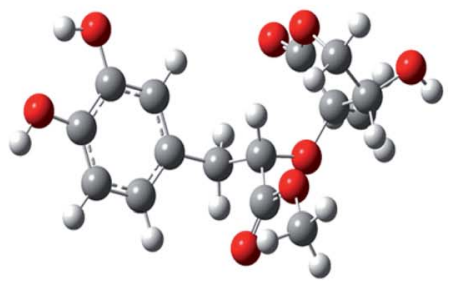

$\operatorname{MO2}\left(\Delta \mathrm{G}^{\circ}=3.9,0.14 \%\right)$

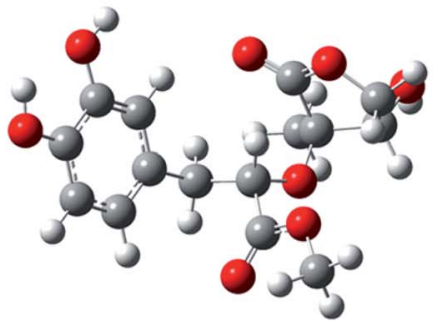

$\operatorname{MO4}\left(\Delta G^{\circ}=5.5,0.01 \%\right)$

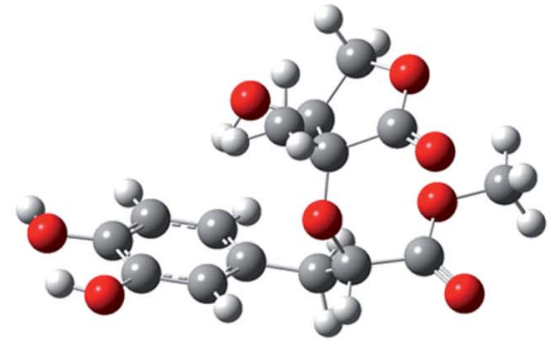

$\operatorname{MO5}\left(\Delta \mathrm{G}^{\circ}=7.1,0.00 \%\right)$

Fig. 2 The typical $M O$ conformers and the relative free energy $\Delta G^{\circ}$ (compared with $M O, \mathrm{kcal} \mathrm{mol}^{-1}$ ). 
Table 1 Calculated thermodynamic parameters $\left(\mathrm{kcal} \mathrm{mol}^{-1}\right)$ of the $\mathrm{MO}+\mathrm{HOO}^{*}$ via $\mathrm{FHT}$, SP and SET reactions

\begin{tabular}{|c|c|c|c|c|c|c|}
\hline \multirow[b]{2}{*}{ Positions } & \multicolumn{2}{|l|}{ FHT } & \multicolumn{2}{|l|}{ SP } & \multicolumn{2}{|l|}{ SET } \\
\hline & $\mathrm{BDE}$ & $\Delta G^{\circ}$ & PA & $\Delta G^{\circ}$ & IE & $\Delta G^{\circ}$ \\
\hline $\mathrm{C} 2-\mathrm{H}$ & 88.4 & 3.6 & & & 185.0 & 162.1 \\
\hline C3-H & 93.0 & 7.6 & & & & \\
\hline O6-H & 79.6 & -5.4 & 334.6 & 183.5 & & \\
\hline $\mathrm{O} 7-\mathrm{H}$ & 79.0 & -6.0 & 332.2 & 181.1 & & \\
\hline O11-H & 104.0 & 18.4 & 353.8 & 201.9 & & \\
\hline C11-H & 98.0 & 11.4 & & & & \\
\hline $\mathrm{C} 12-\mathrm{H}$ & 98.1 & 11.8 & & & & \\
\hline
\end{tabular}

Table 2 Calculated $\Delta G^{\neq}\left(\mathrm{kcal} \mathrm{mol}^{-1}\right)$, tunneling corrections $(\kappa), k_{\text {Eck }}$ $\left(\mathrm{M}^{-1} \mathrm{~s}^{-1}\right)$ and branching ratios $(T, \%)$ for the $\mathrm{HOO}+\mathrm{MO}$ reaction

\begin{tabular}{lrrrr}
\hline Positions & $\Delta G^{\neq}$ & $\kappa$ & \multicolumn{1}{c}{$k_{\text {Eck }}$} & $\Gamma$ \\
\hline O6-H & 12.0 & 169.0 & $1.63 \times 10^{6}$ & 37.5 \\
O7-H & 11.3 & 77.7 & $2.71 \times 10^{6}$ & 62.5 \\
$\boldsymbol{k}_{\text {overall }}$ & & & $4.34 \times \mathbf{1 0}^{6}$ &
\end{tabular}

lowest electronic energy conformers (Fig. 2). It was found that, the lowest $\Delta G^{\circ}$ value was observed at MO, those for MO1-MO5 were higher than that of MO about 3.6-7.1 $\mathrm{kcal} \mathrm{mol}^{-1}$. With the Maxwell-Boltzmann distribution, ${ }^{51,52}$ it was found that MO is the dominant conformer $(99.59 \%)$ in the relative tautomer populations, and this conformer has therefore been used in further studies.

The radical scavenging activity of MO was evaluated against $\mathrm{HOO}^{*}$ radical. This radical species is the simplest of the biologically most important of the ROO', i.e. peroxy radicals, and effective scavenging of these is sufficient to reduce oxidative stress in biological systems. ${ }^{53}$ The HOO ${ }^{\circ}$ radical, which is moderately reactive and one of the main antioxidant objectives, ${ }^{54}$ has been widely used as a reference radical for modeling antioxidant activity in lipid and polar environments. ${ }^{\mathbf{1 2 , 2 1 , 4 8 , 5 5}}$

To understand how MO scavenges free radicals, the antioxidant reactivity of MO was first evaluated following the three typical antioxidant mechanisms, including formal hydrogen transfer (FHT), sequential proton loss electron transfer (SPLET), and single electron transfer proton transfer (SETPT). ${ }^{11}$ Those are defined by the thermochemical parameters (bond dissociation enthalpy (BDE), proton affinity (PA), and ionization energy (IE), respectively). Previous studied showed that the radical adduct formation (RAF) of $\mathrm{HOO}^{\circ}$ radical was not favored for the $\pi$ system of aromatic ring: ${ }^{48,56-58}$ such as in MO and therefore this mechanism was not considered in this study. Therefore, the thermodynamic parameters in the gas phase of MO were computed and results are presented in Table 1.

The lowest BDE values are presented at the phenolic groups, including $\mathrm{O} 6(\mathrm{O} 7)-\mathrm{H}$ bonds with $\mathrm{BDE}=79.6$ and $79.0 \mathrm{kcal} \mathrm{mol} \mathrm{m}^{-1}$, respectively. The BDE of the alcohol group $(\mathrm{O} 11-\mathrm{H})$ is highest at $104.0 \mathrm{kcal} \mathrm{mol}^{-1}$, and this is about $\sim 6$ and $15.6 \mathrm{kcal} \mathrm{mol}^{-1}$ higher than those of the C11(12)-H bonds and $\mathrm{C} 2-\mathrm{H}$ bond, respectively. Calculated thermodynamic parameters in studied solvents (Table $\mathrm{S} 1, \mathrm{ESI} \dagger$ ) indicated that the lowest BDE values were also obtained at the $\mathrm{O} 6(7)-\mathrm{H}$ bonds $(\mathrm{BDE}(\mathrm{O} 6(7)-\mathrm{H})=79.7,79.0$ and 82.6, 82.0 in pentyl ethanoate and water, respectively). Thus the results suggest that the $\mathrm{O} 6(\mathrm{O} 7)-\mathrm{H}$ bonds will define the $\mathrm{H}$-abstraction of MO following the FHT mechanism. It is clear from Table 1 that the PA and IE values are much higher than the BDEs. The lowest PA (PA(O7$\mathrm{H})=332.2 \mathrm{kcal} \mathrm{mol}^{-1}$ ) and IE values are around 4.21 and 2.34 times greater than the lowest BDE. Thus the radical scavenging of MO in the gas phase may be followed the FHT pathway rather than the SETPT and SPLET mechanisms. This result was confirmed by investigating the Gibbs free energies of the reaction between $\mathrm{MO}$ and $\mathrm{HOO}^{\circ}$ radicals (Table 1). ${ }^{259}$ The HOO${ }^{\circ}$ trapping activity of $\mathbf{M O}$ is spontaneous for FHT at O6(7)-H bonds $\left(\Delta G^{\circ}=-5.4\right.$ and $-6.0 \mathrm{kcal} \mathrm{mol}^{-1}$, respectively), whereas the other reactions are unspontaneous with high positive $\Delta G^{\circ}$ values. Based on the calculated data, the $\mathbf{M O}+\mathrm{HOO}^{\circ}$ reaction may only follow the FHT mechanism, and thus this pathway should be investigated in the kinetic study.

In the next step evaluation of the $\mathrm{HOO}^{*}$ trapping activity of MO, the kinetics of the $\mathrm{HOO}^{\circ}+$ MO reaction following the primary mechanism (FHT at O6(7)-H bonds) in the gas phase were computed according to the (QM-ORSA) protocol, ${ }^{12,21}$ the results are shown in Table 2 and Fig. 3. It was found that MO exhibited moderate hydroperoxyl antiradical activity with $k_{\mathrm{Eck}}=$ $1.63 \times 10^{6}$ and $2.71 \times 10^{6} \mathrm{M}^{-1} \mathrm{~s}^{-1}$ for the $\mathrm{O} 6-\mathrm{H}$ and $\mathrm{O} 7-\mathrm{H}$ bonds, respectively. These reactions contribute about 37.5 and $62.5 \%$ in the overall rate constant $\left(k_{\text {overall }}=4.34 \times 10^{6} \mathrm{M}^{-1} \mathrm{~s}^{-1}\right)$. However, the $k_{\text {overall }}$ of the $\mathrm{HOO}^{\circ}+$ MO reaction in the gas phase is $\sim 4.3$ times lower than that of Trolox $\left(k=1.87 \times 10^{7} \mathrm{M}^{-1}\right.$

Table 3 Calculated $\Delta G^{\neq}\left(\mathrm{kcal} \mathrm{mol}^{-1}\right)$ and rate constants $\left(k_{\mathrm{app}}, k_{\mathrm{f}}\right.$, and $\left.k_{\text {overall }} \mathrm{M}^{-1} \mathrm{~s}^{-1}\right)$ at $298.15 \mathrm{~K}$, in the first process of $\mathrm{MO}+\mathrm{HOO}$ reaction

\begin{tabular}{|c|c|c|c|c|c|c|c|c|c|c|c|}
\hline \multirow{2}{*}{\multicolumn{2}{|c|}{ Mechanisms }} & \multicolumn{4}{|c|}{ Pentyl ethanoate } & \multicolumn{6}{|c|}{ Water } \\
\hline & & $\Delta G^{\neq}$ & $\kappa$ & $k_{\text {app }}$ & $\Gamma$ & $\Delta G^{\neq}$ & $\kappa$ & $k_{\text {app }}$ & $f$ & $k_{\mathrm{f}}$ & $\Gamma$ \\
\hline FHT & $\mathrm{O} 6-\mathrm{H}$ & 15.3 & 175.3 & $6.40 \times 10^{3}$ & 25.2 & 16.1 & 932.1 & $8.50 \times 10^{3}$ & 0.961 & $8.17 \times 10^{3}$ & 0.0 \\
\hline$k_{\text {overal }}$ & $\mathrm{O} 7-\mathrm{H}$ & 14.2 & 79.5 & $\begin{array}{l}1.90 \times 10^{4} \\
2.54 \times 10^{4}\end{array}$ & 74.8 & 15.0 & 312.8 & $2.10 \times 10^{4}$ & 0.961 & $\begin{array}{l}2.02 \times 10^{4} \\
1.05 \times 10^{8}\end{array}$ & 0.0 \\
\hline
\end{tabular}

${ }^{a}$ The nuclear reorganization energy $\left(\lambda, \mathrm{kcal} \mathrm{mol}^{-1}\right) ; f=\% \mathrm{~A}^{-} / 100 ; k_{\mathrm{f}}=f k_{\mathrm{app}} ; \Gamma=k_{\mathrm{f}} \times 100 / k_{\text {overall }}$. 
$\left.\mathrm{S}^{-1}\right) .{ }^{60}$ Hence, it appears to suggest that the hydroperoxyl antiradical activity of MO in nonpolar media might be lower than that of Trolox.

\subsection{The $\mathrm{HOO}^{\circ}$ radical trapping activity of $\mathrm{MO}$ in} physiological environments

3.2.1 The first process. In aqueous environments, the radical scavenging activity of acidic species is typically dominated by the activity of the ionic forms. ${ }^{18,59}$ Therefore, the protonation state of MO was first evaluated at physiological $\mathrm{pH}$ to find the most likely radical scavenging reactions. The thermodynamic section and the calculations for water medium (Table S1, ESI $, \uparrow\left(\mathrm{PA}(\mathrm{O} 6-\mathrm{H})=43.1 \mathrm{kcal} \mathrm{mol}^{-1}\right), \mathrm{PA}(\mathrm{O} 7-\mathrm{H})=$ $42.9 \mathrm{kcal} \mathrm{mol}^{-1}$ ) showed that deprotonation was the easiest at the $\mathrm{O} 7-\mathrm{H}$ bond; thus, the $\mathrm{p} K_{\mathrm{a}}$ value of MO was computed for the $\mathrm{O} 7-\mathrm{H}$ bond based on the literature ${ }^{59,61}$ and shown in Fig. 4.

The calculated $\mathrm{p} K_{\mathrm{a}}$ value was $\mathrm{p} K_{\mathrm{a}}=8.79$. Therefore, in $\mathrm{pH}=$ 7.40 aqueous solutions, MO exists in two states, including the neutral (HA, 96.1\%) and anion $\left(\mathrm{A}^{-}, 3.9 \%\right)$ states. Hence, these states were used in the kinetic study of the HOO trapping activity of $\mathrm{MO}$ in water at $\mathrm{pH}=7.4$. The overall rate constant $\left(k_{\text {overall }}\right)$ of $\mathrm{HOO}^{*}+$ MO reaction in the first antiradical process were calculated according to eqn (7) and (8); the results are presented in Table 3 and Fig. 3, while the potential energy

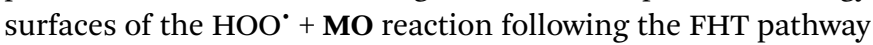
is shown in Fig. 5.

In lipid medium: $v=-2003.73$

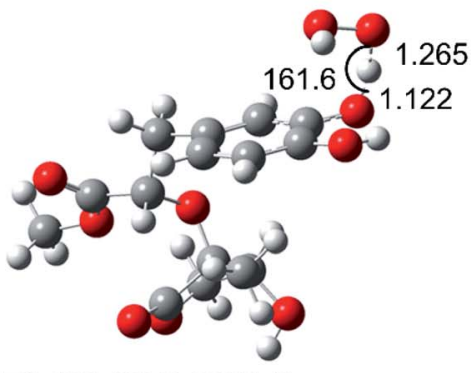

TS-MO-O6-H-OOH-G

$\nu=-1843.26$

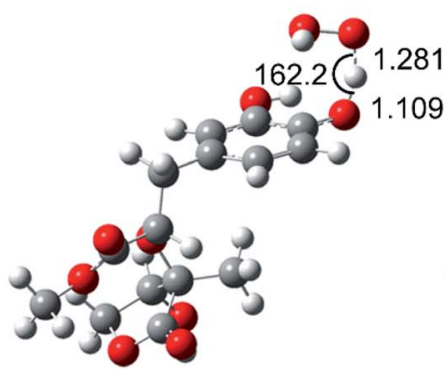

TS-MO-O7-H-OOH-G

$v=-2974.71$

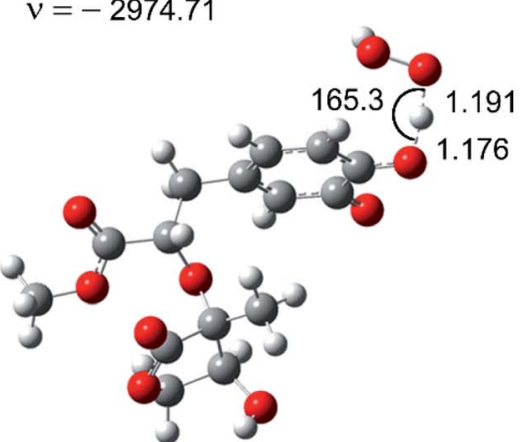

TS-MÖ6-O7-H-OOH-P $v=-1969.30$

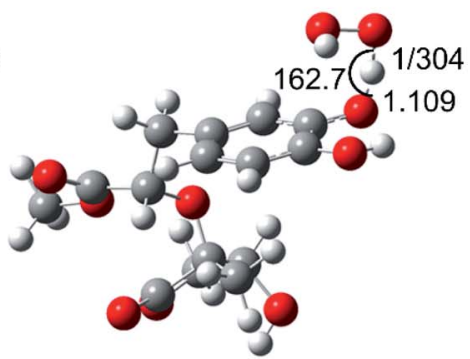

TS-MO-O6-H-OOH-P

$v=-1898.310$

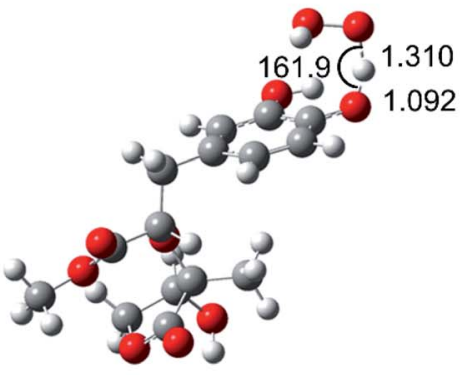

TS-MO-O7-H-OOH-P

$v=-3202.24$

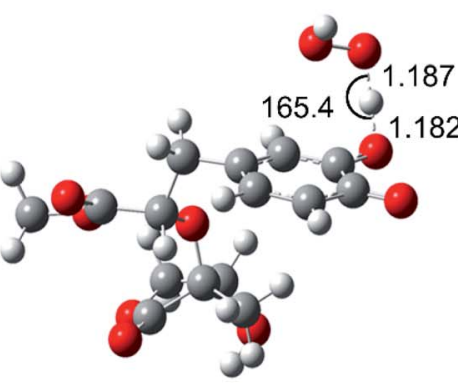

TS-MÖ7-O6-H-OOH-P

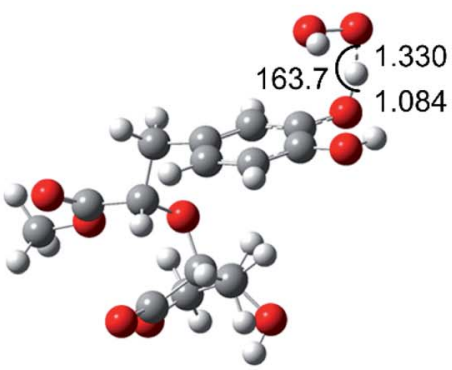

TS-MO-O6-H-OOH-W

$v=-2267.20$

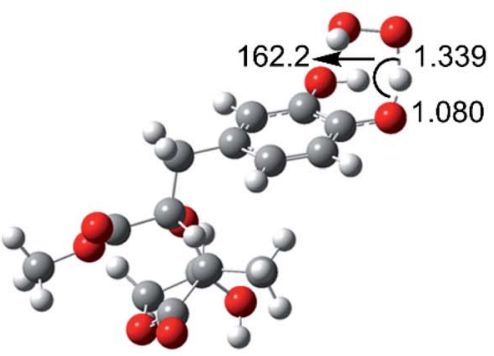

TS-MO-O7-H-OOH-W

$v=-2746.82$

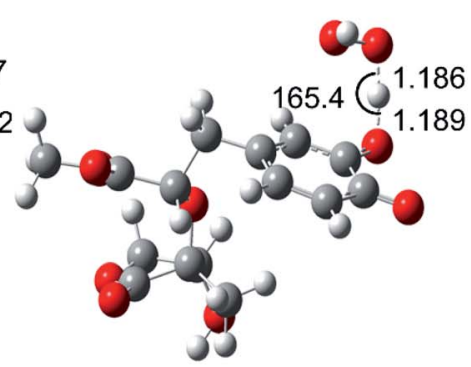

TS-MÖ7-06-H-OOH-W

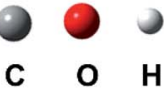

Fig. 3 Optimized geometries of FHT TSs of the HOO + MO reaction (G: gas phase, W: water, P: pentyl ethanoate). 
Table 4 Calculated thermodynamic parameters $\left(\mathrm{kcal} \mathrm{mol}^{-1}\right)$ of the intermediates + $\mathrm{HOO}^{\circ}$ via $\mathrm{FHT}$ and SET mechanisms in pentyl ethanoate $(\mathrm{P})$ and water $(\mathrm{W})$

\begin{tabular}{|c|c|c|c|c|c|c|}
\hline \multirow[b]{2}{*}{ Solvents } & \multirow[b]{2}{*}{ Intermediates } & \multirow[b]{2}{*}{ Positions } & \multicolumn{2}{|l|}{ FHT } & \multicolumn{2}{|l|}{ SET } \\
\hline & & & $\mathrm{BDE}$ & $\Delta G^{\circ}$ & IE & $\Delta G^{\circ}$ \\
\hline \multirow[t]{2}{*}{$\mathrm{P}$} & MO-O6 ${ }^{\circ}$ & $\mathrm{O} 7-\mathrm{H}$ & 69.2 & -16.4 & 145.9 & 75.8 \\
\hline & MO-O7 & $\mathrm{O} 6-\mathrm{H}$ & 69.9 & -16.0 & 143.9 & 72.5 \\
\hline $\mathrm{W}$ & MO-O7 & $\mathrm{O} 6-\mathrm{H}$ & 71.1 & -18.8 & 132.0 & 26.3 \\
\hline
\end{tabular}

$$
k_{\text {overall }}=k_{\text {app }}(\mathrm{FHT}(\mathrm{O} 6-\mathrm{H}) \text {-neutral })
$$$$
+k_{\text {app }}(\mathrm{FHT}(\mathrm{O} 7-\mathrm{H}) \text {-neutral })
$$

In the aqueous medium:

$$
\begin{aligned}
k_{\text {overall }}= & k_{\mathrm{f}}(\mathrm{SET} \text {-anion })+k_{\mathrm{f}}(\mathrm{FHT}(\mathrm{O} 6-\mathrm{H}) \text {-neutral }) \\
& +k_{\mathrm{f}}(\mathrm{FHT}(\mathrm{O} 7-\mathrm{H}) \text {-neutral })
\end{aligned}
$$

As shown in Fig. 5, in the first antiradical process, the reaction proceeds via the RCs that are more stable in terms of energy than the reactants about $3.4-5.8 \mathrm{kcal} \mathrm{mol}^{-1}$. Then, the reaction can proceed to TSs from the RCs (the energy barriers around 12.0-17.0 kcal $\mathrm{mol}^{-1}$ ) before bottoming the lowest energy points (PCs) and forming the products. The energy barriers for the MO-O6- $\mathrm{H}+\mathrm{HOO}^{\circ}$ reaction in water and pentyl ethanoate are higher (from 0.3 to $2.1 \mathrm{kcal} \mathrm{mol}^{-1}$, respectively) than those of the MO-O7-H + $\mathrm{HOO}^{\circ}$ reaction. This suggests that the $\mathrm{H}$-abstraction of the $\mathrm{O} 7-\mathrm{H}$ bond against $\mathrm{HOO}^{\circ}$ radicals should be faster than that of the O6-H bond.

It is clear from the Table 3 that the hydroperoxyl radical trapping activity of MO in pentyl ethanoate is moderate with the $k_{\text {overall }}=2.54 \times 10^{4} \mathrm{M}^{-1} \mathrm{~s}^{-1}$ by the $\mathrm{H}$-abstractions of the O6-H $(\Gamma=25.2 \%)$ and $\mathrm{O} 7-\mathrm{H}$ bonds $(\Gamma=74.8 \%)$. In contrast, MO exhibits an excellent $\mathrm{HOO}^{\circ}$ trapping activity in the polar medium with the $k_{\text {overall }}=1.05 \times 10^{8} \mathrm{M}^{-1} \mathrm{~s}^{-1}$. This process was defined by the SET reaction of the anion state (MO-O7 ${ }^{-}, \Gamma \sim$ $100 \%)$. The rate constants for the FHT reaction of the O6(7)-H bonds against $\mathrm{HOO}^{\circ}$ radical in water are $k_{\mathrm{f}}=8.17 \times 10^{3}(2.02 \times$ $\left.10^{4}\right) \mathrm{M}^{-1} \mathrm{~s}^{-1}$, whereas these reactions make negligible contributions $(\sim 0 \%)$ to the overall $\mathrm{HOO}^{*}$ antiradical activity of MO. However, the reaction at the $\mathrm{O} 7-\mathrm{H}$ bond is faster than that the $\mathrm{O} 6-\mathrm{H}$ bond in all of the studied media. This is in good agreement with the PES analysis results. Compared with the reference antioxidant Trolox $\left(k=1.00 \times 10^{5}\right.$ and $1.30 \times 10^{5} \mathrm{M}^{-1}$ $\mathrm{s}^{-1}$ in pentyl ethanoate and water, respectively), ${ }^{60}$ the HOO trapping activity of MO is fairly lower in the lipid medium but about 808 times higher in water at physiological $\mathrm{pH}$.

3.2.2 The second process of the radical scavenging. To gain further insights into the antioxidant of MO in the physiological environments, the hydroperoxyl radical scavenging activity of MO intermediates (the second antiradical process of MO) in pentyl ethanoate and water was investigated. As shown in the first reaction step, the primary intermediates of $\mathbf{M O}+\mathrm{HOO}^{\circ}$ reaction in pentyl ethanoate were MO-O6 $^{*}(25.2 \%)$ and MO-O7 ${ }^{*}$ $(74.8 \%)$ radicals, while that for the aqueous solution was MO$\mathrm{O}^{\bullet}(100.0 \%)$. Thus these intermediates were used as reactants for the second reaction against $\mathrm{HOO}^{*}$ radicals. The thermodynamic parameters (BDEs, IE) were computed for the most active positions and are shown in Table 4.

As shown in Table 4, the BDE values of the most active positions (O6- $\mathrm{H}$ and $\mathrm{O} 7-\mathrm{H}$ bonds) are in the range of 69.2 to $71.1 \mathrm{kcal} \mathrm{mol}^{-1}$, much lower than those of MO in the first step (Table 1). At the same time, the calculated IE values of inter-

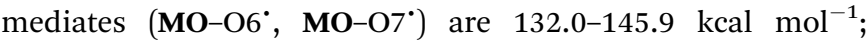<smiles>COC(=O)C(Cc1ccc(O)c(O)c1)OC1(C)C(=O)OCC1O</smiles>

$96.1 \%$

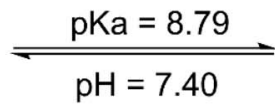
$\mathrm{H}$<smiles>COC(=O)C(Cc1ccc([O-])c(O)c1)OC1(C)C(=O)OCC1O</smiles>

$3.9 \%$

Fig. 4 The deprotonation of $\mathrm{MO}$ at $\mathrm{pH}=7.4$.

Table 5 Calculated $\Delta G^{\neq}\left(\mathrm{kcal} \mathrm{mol}^{-1}\right)$ and rate constants $\left(k_{\mathrm{f}}\right.$, and $\left.k_{\text {overall }} \mathrm{M}^{-1} \mathrm{~s}^{-1}\right)$ at $298.15 \mathrm{~K}$, in the second process of $\mathrm{MO}+\mathrm{HOO}$ reaction ${ }^{a}$

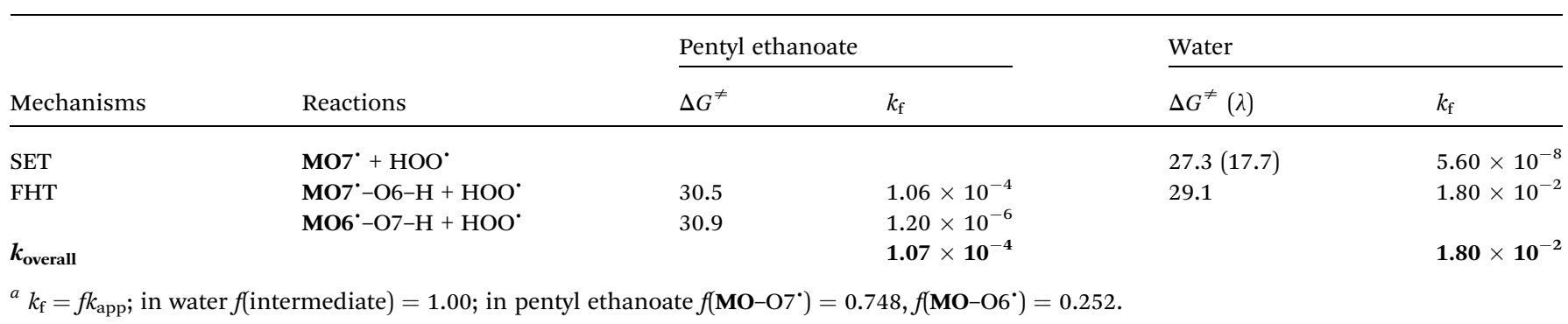



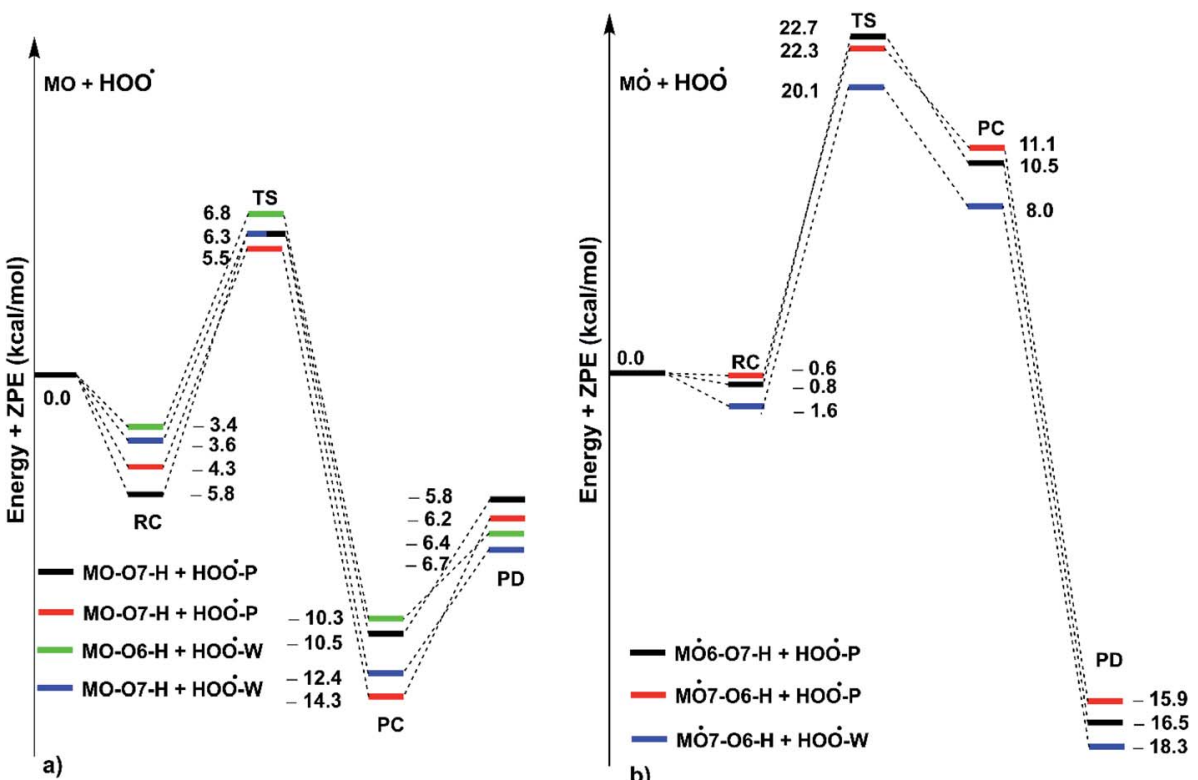

Fig. 5 PES of reactions between $\mathrm{MO}$ and $\mathrm{HOO}^{\circ}$ in pentyl ethanoate $(\mathrm{P})$ and water $(\mathrm{W})$ in double processes ((a): the first step; (b) the second step; RC: pre-complexes, TS: transition states, PC: post-complexes, PD: products).

however, the SET mechanism is not favored for the intermediates due to the large positive $\Delta G^{\circ}\left(\Delta G^{\circ}=26.3-75.8 \mathrm{kcal} \mathrm{mol}^{-1}\right)$. Thus the $\mathrm{HOO}^{\circ}$ radical scavenging activity of intermediates was defined by the FHT pathway $\left(\Delta G^{\circ}<0\right.$, Table 4$)$; thus, these reactions were used for kinetic investigating.

Previous studies also showed that the reaction between antiradical intermediates with radical i.e., $\mathrm{HO}^{*}$ and $\mathrm{HOO}^{\circ}$ most probably proceeds through triplet transition states, ${ }^{\mathbf{5 5 , 6 2}}$ and thus, the result was used to evaluate the mechanism and kinetics of the second antiradical reaction of MO. The potential energy surfaces are shown in Fig. 5, whereas the possible mechanisms and kinetic data are presented in Fig. 5 and Table 4 , respectively.
As shown in Fig. 5, the reactions of intermediates (MO-O6 and $\mathrm{MO}^{-} \mathrm{O7}^{\circ}$ ) and $\mathrm{HOO}^{\circ}$ radicals proceed via $\mathrm{RCs}$, TSs and PCs, while the PC species are less stable in terms of energy than the reactants. This is in line with previous studies in phenolic compounds. ${ }^{55,62}$ The energy barriers of the reactions are about 20.1-22.7 $\mathrm{kcal} \mathrm{mol}^{-1}$, which is much higher than those of the first step (the energy barriers around 12.0-17.0 kcal mol $\mathrm{k}^{-1}$, Table 5). The overall rate constants of the intermediates (MO$\mathrm{O}^{\circ}{ }^{\circ}$ or MO$\left.-\mathrm{O}^{*}\right)+\mathrm{HOO}^{*}$ reactions in pentyl ethanoate is $1.07 \times$ $10^{-4} \mathrm{M}^{-1} \mathrm{~S}^{-1}$, while that for the aqueous solution is $1.80 \times 10^{-2}$ $\mathrm{M}^{-1} \mathrm{~s}^{-1}$. Thus the HOO ${ }^{\circ}$ radical scavenging activity in the second reaction step of MO following the FHT pathway is about $10^{6}-10^{8}$ times lower than those of the first reaction step (Fig. 6),

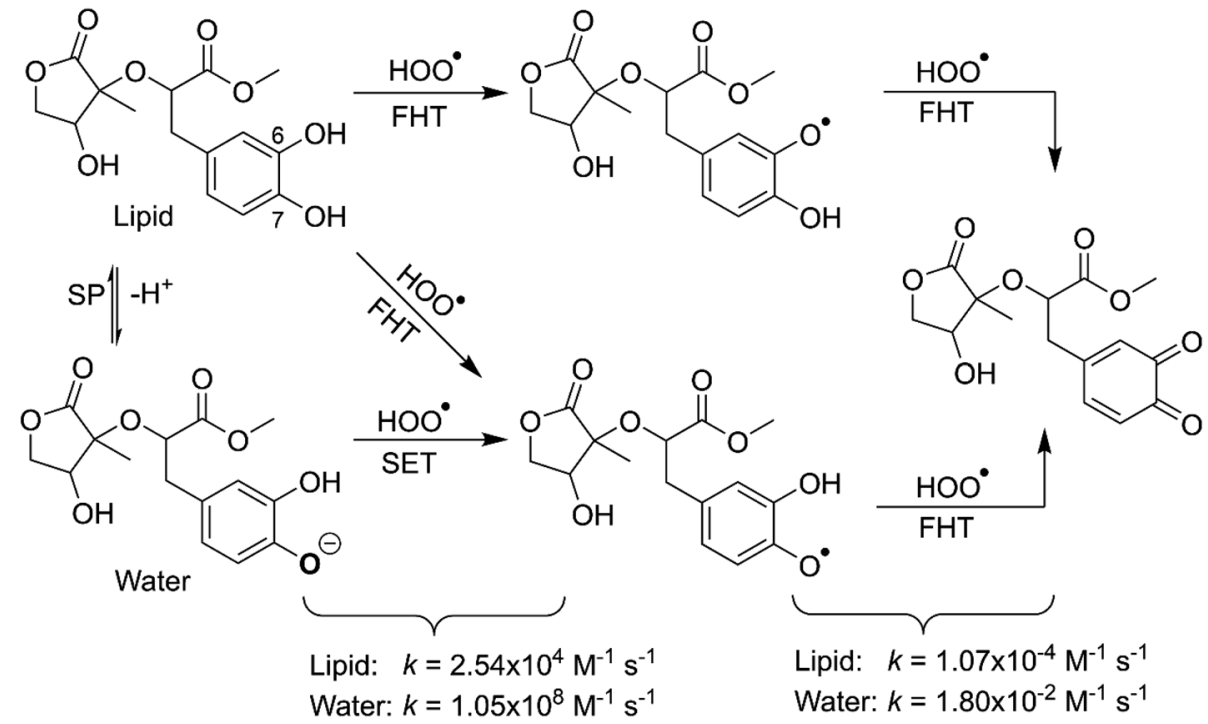

Fig. 6 The possible mechanisms for the $\mathrm{HOO}^{*}+\mathrm{MO}$ reaction in the physiological environment. 
despite of the fact that the $\operatorname{BDE}(\mathrm{O}-\mathrm{H})$ values at the intermediates (BDEs $=69.2-71.1 \mathrm{kcal} \mathrm{mol}^{-1}$, Table 4) are lower than those of MO (Table 1) by about $10 \mathrm{kcal} \mathrm{mol}^{-1}$, and the Gibbs free energies for the intermediates (MO-O6 ${ }^{\circ}$ or MO-O7 $\left.^{\circ}\right)+\mathrm{HOO}^{*}$ reactions are $\Delta G^{\circ}=-16.0$ to $-18.8 \mathrm{kcal} \mathrm{mol}^{-1}$ (Table 4 ). These results suggest that the $\mathrm{HOO}^{\circ}$ radical scavenging of $\mathrm{MO}$ at the second process is supported by the thermodynamic properties (the low BDE values and $\Delta G^{\circ}<0$ ); however, this reaction hardly occurs due to the low rate constant values. Thus the antiradical activity should be considered in both thermodynamic and kinetic data rather than based on thermodynamic considerations alone. Based on the calculated data, the HOO ${ }^{*}$ trapping activity of MO in nonpolar and polar environments was mainly defined by the first step.

\section{Conclusion}

The hydroperoxyl radical scavenging activity of muriolide in the physiological environment has been successfully investigated in silico. The result showed that MO exhibited moderate activity ( $k$ $=2.54 \times 10^{4} \mathrm{M}^{-1} \mathrm{~s}^{-1}$ ) in the nonpolar media, whereas the activity was excellent with $k=1.05 \times 10^{8} \mathrm{M}^{-1} \mathrm{~s}^{-1}$ in water under the physiological $\mathrm{pH}$. The antiradical reactions could occur in two steps; however, the first step reaction defined the HOO radical scavenging activity of MO. In nonpolar conditions, the FHT mechanism via the $\mathrm{O} 6-\mathrm{H}$ and $\mathrm{O} 7-\mathrm{H}$ bonds determined the antiradical activity, whereas the SET mechanism of the anionic state defined the activity in the polar medium. The $\mathrm{HOO}^{\circ}+$ MO reaction in pentyl ethanoate is slightly lower than Trolox, but it is approximately 808 times faster than that of the reference in the aqueous solution. Thus, MO is an effective radical scavenger in the physiological environment.

\section{Conflicts of interest}

There are no conflicts to declare.

\section{Acknowledgements}

This research is funded by the Vietnamese Ministry of Education and Training under project number B2021-DNA-16 (Q. V. $\mathrm{V})$.

\section{References}

1 B.-L. Wu, H.-L. Zou, F.-M. Qin, H.-Y. Li and G.-X. Zhou, Molecules, 2015, 20, 22445-22453.

2 H. Iqbal, Z. Sher and Z. U. Khan, J. Med. Plants Res., 2011, 5, 2157-2168.

3 M. Ullah, M. U. Khan, A. Mahmood, R. N. Malik, M. Hussain, S. M. Wazir, M. Daud and Z. K. Shinwari, J. Ethnopharmacol., 2013, 150, 918-924.

4 M. Umair, M. Altaf and A. M. Abbasi, PLoS One, 2017, 12, e0177912.

5 J. Khan, R. Khan and R. Qureshi, J. Med. Plants Stud., 2013, 1, 1-6.
6 H. Sher and M. Alyemeni, Afr. J. Biotechnol., 2011, 10, 91539159.

7 F. A. Khan, M. Zahoor and E. Khan, Pak. J. Pharm. Sci., 2016, 29, 503-510.

8 S. Nazir, K. Tahir, R. Naz, Z. Khan, A. Khan, R. Islam and A. U. Rehman, J. Pharmacol., 2014, 8, 427-431.

9 N. Raziq, M. Saeed, M. S. Ali, M. Lateef, M. Shahid, S. Akbar and S. Zafar, Nat. Prod. Res., 2020, 1-7.

10 F. Azam, B. A. Chaudhry, H. Ijaz and M. I. Qadir, Sci. Rep., 2019, 9, 1-6.

11 K. U. Ingold and D. A. Pratt, Chem. Rev., 2014, 114, 90229046.

12 A. Galano and J. Raúl Alvarez-Idaboy, Int. J. Quantum Chem., 2019, 119, e25665.

13 C. S. Challa, N. K. Katari, V. Nallanchakravarthula, D. Nayakanti, R. Kapavarapu and M. Pal, J. Mol. Struct., 2021, 1245, 131069.

14 G. Dhananjaya, A. D. Rao, K. A. Hossain, V. R. Anna and M. Pal, Tetrahedron Lett., 2020, 61, 151972.

15 Q. V. Vo, T. V. Gon, M. V. Bay and A. Mechler, J. Phys. Chem. $B, 2019,123,10672-10679$.

16 M. J. Frisch, G. W. Trucks, H. B. Schlegel, G. E. Scuseria, M. A. Robb, J. R. Cheeseman, G. Scalmani, V. Barone, B. Mennucci, G. A. Petersson, H. Nakatsuji, M. Caricato, X. Li, A. F. I. H. P. Hratchian, J. Bloino, G. Zheng, M. H. J. L. Sonnenberg, M. Ehara, K. Toyota, J. H. R. Fukuda, M. Ishida, T. Nakajima, Y. Honda, H. N. O. Kitao, T. Vreven, J. A. Montgomery, Jr, F. O. J. E. Peralta, M. J. Bearpark, J. Heyd, K. N. K. E. N. Brothers, V. N. Staroverov, R. Kobayashi, K. R. J. Normand, A. P. Rendell, J. C. Burant, J. T. S. S. Iyengar, M. Cossi, N. Rega, N. J. Millam, J. E. K. M. Klene, J. B. Cross, V. Bakken, C. Adamo, R. G. J. Jaramillo, R. E. Stratmann, O. Yazyev, R. C. A. J. Austin, C. Pomelli, J. W. Ochterski, K. M. R. L. Martin, V. G. Zakrzewski, G. A. Voth, J. J. D. P. Salvador, S. Dapprich, A. D. Daniels, J. B. F. Ö. Farkas, J. V. Ortiz, J. Cioslowski, and D. J. Fox, Gaussian 09, Gaussian, Inc., Wallingford CT, 2009.

17 Y. Zhao and D. G. Truhlar, Theor. Chem. Acc., 2008, 120, 215241.

18 A. Galano and J. R. Alvarez-Idaboy, J. Comput. Chem., 2014, 35, 2019-2026.

19 Y. Zhao and D. G. Truhlar, J. Phys. Chem. A, 2008, 112, 10951099.

20 M. Carreon-Gonzalez, A. Vivier-Bunge and J. R. AlvarezIdaboy, J. Comput. Chem., 2019, 40, 2103-2110.

21 A. Galano and J. R. Alvarez-Idaboy, J. Comput. Chem., 2013, 34, 2430-2445.

22 J. R. l. Alvarez-Idaboy and A. Galano, J. Phys. Chem. B, 2012, 116, 9316-9325.

23 M. E. Alberto, N. Russo, A. Grand and A. Galano, Phys. Chem. Chem. Phys., 2013, 15, 4642-4650.

24 E. Dzib, J. L. Cabellos, F. Ortíz-Chi, S. Pan, A. Galano and G. Merino, Int. J. Quantum Chem., 2019, 119, e25686. 
25 H. Boulebd, I. Amine Khodja, M. V. Bay, N. T. Hoa, A. Mechler and Q. V. Vo, J. Phys. Chem. B, 2020, 124, 41234131.

26 C. P. Kelly, C. J. Cramer and D. G. Truhlar, J. Chem. Theory Comput., 2005, 1, 1133-1152.

27 E. Dzib, J. L. Cabellos, F. Ortiz-Chi, S. Pan, A. Galano and G. Merino, Eyringpy 1.0.2, Cinvestav, Mérida, Yucatán, 2018.

28 M. G. Evans and M. Polanyi, Trans. Faraday Soc., 1935, 31, 875-894.

29 H. Eyring, J. Chem. Phys., 1935, 3, 107-115.

30 D. G. Truhlar, W. L. Hase and J. T. Hynes, J. Phys. Chem., 1983, 87, 2664-2682.

31 T. Furuncuoglu, I. Ugur, I. Degirmenci and V. Aviyente, Macromolecules, 2010, 43, 1823-1835.

32 E. Vélez, J. Quijano, R. Notario, E. Pabón, J. Murillo, J. Leal, E. Zapata and G. Alarcón, J. Phys. Org. Chem., 2009, 22, 971977.

33 E. Pollak and P. Pechukas, J. Am. Chem. Soc., 1978, 100, 2984-2991.

34 A. Fernández-Ramos, B. A. Ellingson, R. Meana-Pañeda, J. M. Marques and D. G. Truhlar, Theor. Chem. Acc., 2007, 118, 813-826.

35 C. Eckart, Phys. Rev., 1930, 35, 1303.

36 R. A. Marcus, Annu. Rev. Phys. Chem., 1964, 15, 155-196.

37 R. A. Marcus, Rev. Mod. Phys., 1993, 65, 599.

38 Y. Lu, A. Wang, P. Shi, H. Zhang and Z. Li, PLoS One, 2015, 10, e0133259.

39 S. F. Nelsen, S. C. Blackstock and Y. Kim, J. Am. Chem. Soc., 1987, 109, 677-682.

40 S. F. Nelsen, M. N. Weaver, Y. Luo, J. R. Pladziewicz, L. K. Ausman, T. L. Jentzsch and J. J. O'Konek, J. Phys. Chem. A, 2006, 110, 11665-11676.

41 F. C. Collins and G. E. Kimball, J. Colloid Sci., 1949, 4, 425437.

42 M. Von Smoluchowski, Z. Phys. Chem., 1917, 92, 129-168.

43 D. G. Truhlar, J. Chem. Educ., 1985, 62, 104.

44 A. Einstein, Ann. Phys., 1905, 17, 549-560.

45 G. G. Stokes, Mathematical and Physical Papers, University Press, Cambridge, 1905.
46 Y. Okuno, Chem.-Eur. J., 1997, 3, 212-218.

47 S. Benson, The Foundations of Chemical Kinetics, Malabar, Florida, 1982.

48 C. Iuga, J. R. Alvarez-Idaboy and A. Vivier-Bunge, J. Phys. Chem. B, 2011, 115, 12234-12246.

49 J. R. Alvarez-Idaboy, L. Reyes and N. Mora-Diez, Org. Biomol. Chem., 2007, 5, 3682-3689.

50 W. Hehre, J. Yu, P. Klunzinger and L. Lou, Spartan Software, Wavefunction.Inc., Irvine, 2000.

51 A. Galano and J. R. Alvarez-Idaboy, RSC Adv., 2011, 1, 17631771.

52 Q. V. Vo, N. M. Tam, M. Van Bay, N. M. Thong, T. Le Huyen, N. T. Hoa and A. Mechler, RSC Adv., 2020, 10, 14937-14943.

53 P. Terpinc and H. Abramovič, Food Chem., 2010, 121, 366371.

54 T. Masuda, K. Yamada, T. Maekawa, Y. Takeda and H. Yamaguchi, J. Agric. Food Chem., 2006, 54, 6069-6074.

55 D. S. Dimić, D. A. Milenković, E. H. Avdović, Đ. J. Nakarada, J. M. D. Marković and Z. S. Marković, Chem. Eng. Sci., 2021, 130331.

56 M. Cordova-Gomez, A. Galano and J. R. Alvarez-Idaboy, RSC Adv., 2013, 3, 20209-20218.

57 C. Iuga, J. R. 1. Alvarez-Idaboy and N. Russo, J. Org. Chem., 2012, 77, 3868-3877.

58 Q. V. Vo, P. C. Nam, M. Van Bay, N. M. Thong and A. Mechler, RSC Adv., 2019, 9, 42020-42028.

59 H. Boulebd, A. Mechler, N. T. Hoa and Q. V. Vo, New J. Chem., 2020, 44, 9863-9869.

60 Q. V. Vo, N. M. Thong, T. Le Huyen, P. C. Nam, N. M. Tam, N. T. Hoa and A. Mechler, RSC Adv., 2020, 10, 20089-20097.

61 A. Galano, A. Pérez-González, R. Castañeda-Arriaga, L. Muñoz-Rugeles, G. Mendoza-Sarmiento, A. RomeroSilva, A. Ibarra-Escutia, A. M. Rebollar-Zepeda, J. R. LeónCarmona, M. A. Hernández-Olivares and J. R. AlvarezIdaboy, J. Chem. Inf. Model., 2016, 56, 1714-1724.

62 D. A. Milenković, D. S. Dimić, E. H. Avdović, A. D. Amić, J. M. D. Marković and Z. S. Marković, Chem. Eng. Sci., 2020, 395, 124971. 